\title{
Separation of Scandium from Hydrochloric Acid-Ethanol Leachate of Bauxite Residue by a Supported Ionic Liquid Phase
}

\author{
Dženita Avdibegović and Koen Binnemans*
}

Cite This: Ind. Eng. Chem. Res. 2020, 59, 15332-15342

Read Online

ABSTRACT: Solvometallurgy is a new branch of extractive metallurgy in which green organic solvents are used instead of aqueous solutions to improve selectivity in separation processes. In the present study, nonaqueous leaching of a Greek bauxite residue (BR) was performed and scandium was separated from other elements in the leachate by column chromatography. At first, the selectivity of sorbents for scandium(III) over iron(III) was tested in batch mode using various organic solvents. The following three sorbents were tested: (1) a carboxylic acid-functionalized supported ionic liquid phase (SILP), (2) silica $\left(\mathrm{SiO}_{2}\right)$, and (3) silica functionalized with ethylenediaminetetraacetic acid $\left(\mathrm{SiO}_{2}-\mathrm{TMS}-\mathrm{EDTA}\right)$. The best separation of scandium and iron was achieved from ethanolic solution by the SILP. The BR was then leached with $0.7 \mathrm{~mol} \mathrm{~L}^{-1}$ $\mathrm{HCl}$ in ethanol or in water. The leaching efficiency of scandium with both lixiviants was similar. However, much less sodium was leached, and silica remained in solution when leaching was performed with the ethanolic lixiviant. By using ethanol as opposed to water, the serious drawback of silica gel formation that is taking place in the aqueous leachate of BR was circumvented. The sorption preference of the SILP for metal ions in the ethanolic leachate was partly reversed compared to the aqueous leachate. Iron was separated from other metals of the ethanolic BR leachate by a simple elution with ethanol. The formation of the anionic tetrachloroferrate(III) complex, $\left[\mathrm{FeCl}_{4}\right]^{-}$, enabled the selective elution. This complex was not observed in the aqueous leachate of BR. Scandium was separated from the vast majority of other components of the BR by elution with $0.1 \mathrm{~mol} \mathrm{~L}^{-1} \mathrm{H}_{3} \mathrm{PO}_{4}$.

\section{INTRODUCTION}

Scandium is a scarce and expensive rare-earth element. ${ }^{1}$ As a consequence, its commercial applications are still limited. Its major uses are in solid oxide fuel cells and as an alloying metal for aluminum. The addition of no more than $0.35-0.4 \%$ of scandium to aluminum alloys results in a material with superior mechanical strength. ${ }^{2,3}$ Scandium is rarely found in nature in concentrated ore deposits but is obtained as a byproduct in the extraction processes of other metals such as the rare earths and uranium.

Bauxite residue (BR) or red mud is an alkaline byproduct generated in the Bayer process for production of alumina from bauxite ore. Its global annual average production is estimated at 150 million tonnes. ${ }^{5}$ It is commonly disposed by lagooning or "dry stacking" methods. In the lagooning method, BR slurry is pumped into storage ponds. BR disposed in such a way can create safety and environmental issues, such as contamination of surface and ground waters by leaching of alkaline liquor and other contaminants. ${ }^{5}$ Dry stacking is used as the preferred method for BR disposal in order to reduce the potential for leakage of alkaline liquor and increase the recoveries of soda and alumina. ${ }^{5}$ Both methods for disposal of BR require a substantial area of land, which could be used, for instance, for forests or agriculture. BR has attracted a lot of research attention in the past years as a resource for metals or as a building material. ${ }^{6-12} \mathrm{BR}$ can also be a valuable resource of scandium, but the scandium concentration is dependent on the type and origin of the bauxite ore. ${ }^{13}$ For instance, Greek BR contains around $120 \mathrm{~g}$ tonne $\mathrm{e}^{-1}$ of scandium, which is much higher than the average abundance of scandium in the Earth's crust $\left(22 \mathrm{~g}_{\text {tonne }} \mathrm{e}^{-1}\right)$ and high enough to consider this BR as a resource for scandium recovery. The main metals in BR are iron, aluminum, calcium, sodium, silicon, and titanium, and these elements are present in much higher concentrations than scandium. ${ }^{14}$ Greek BR also contains other rare-earth elements (e.g., yttrium, lanthanum, neodymium) besides scandium, but their economic value in $\mathrm{BR}$ is much lower than that of scandium.

Typically, scandium is recovered from BR by hydrometallurgical methods or by a combination of pyrometallurgical and hydrometallurgical methods. ${ }^{15} \mathrm{BR}$ or its slag after a pyrometallurgical treatment is leached with mineral acids followed by recovery of the dissolved elements in the leachates by precipitation methods, solvent extraction, or ion exchange. ${ }^{15-20}$ Precipitation methods are easily performed but usually result in less pure products. Solvent extraction and ion

Received: June 12, 2020

Revised: July 27, 2020

Accepted: July 28, 2020

Published: July 28, 2020

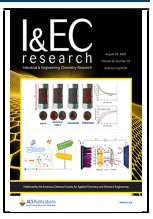


a)<smiles>[R]c1ccc(S(=O)(=O)C[N+](C)(C)CC(=O)O)cc1</smiles>

b)

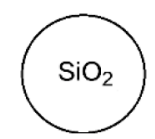

c)

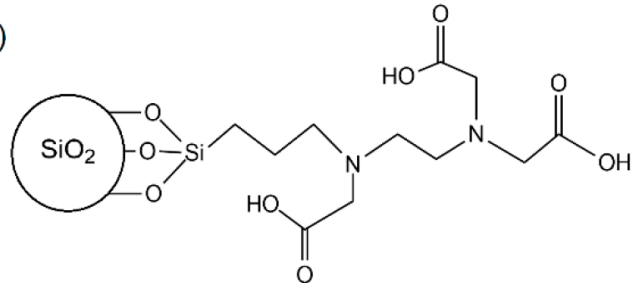

Figure 1. Sorbents tested for scandium recovery from BR leachates: (a) SILP Hbet-STFSI-PS-DVB, (b) silica, and (c) SiO $2-$ TMS-EDTA.

exchange processes showed promising results for scandium recovery from BR. Still, often a pretreatment step for removal of major components (e.g., iron) or the addition of reducing agents is required to enhance the selectivity and maximize the efficiency of the recovery methods. ${ }^{15,19,21}$ The scandium concentrations in BR leachate are much lower than those of the major components such as iron. The separation of scandium(III) from iron(III) is challenging because of the similar chemical properties of these two metal ions. Therefore, highly selective processes are required for concentrating scandium from dilute yet chemically complex streams. Ion exchange column chromatography processes can be useful in concentrating scandium from such feeds. Ideally, the sorbent which is packed in a column would selectively recover elements of interest and reject untargeted elements. However, in most ion-exchange processes for metal recovery from complex, multielement solutions, untargeted components are still cosorbed, which diminishes the efficiency of the sorbent. In addition, the desired metals can strongly bind to a selective sorbent rendering their recovery by elution very difficult. ${ }^{3}$

In ion exchange processes, the selective sorption of scandium is generally optimized based on specific interactions between scandium in the aqueous leachate and functional groups of sorbents, followed by selective elution of impurities and scandium. However, little work has been done on tuning the process for scandium recovery by using nonaqueous solvents for dissolving components of the BR prior to its further processing. A significant difference in efficiency and selectivity for a given ion has been observed when pure organic solvents or their mixtures with mineral acids have been used in ion exchange processes. ${ }^{22-25}$ The importance of organic solvents in extractive metallurgy of valuable metals has been recognized and recently the concept of solvometallurgy was introduced. ${ }^{26}$ Solvometallurgy involves extraction of metals from ores, industrial process residues, production scrap, and urban waste using nonaqueous solutions. The term nonaqueous implies solutions with low water content. Water is replaced by green solvents, which ideally have low toxicity, low flammability, and low environmental impact.

In the present study, the enhancement of the selectivity of sorbents for scandium is investigated by tuning the composition of the solvent in which scandium is dissolved. The selectivity for scandium over iron is investigated in batch mode from aqueous solutions and solutions with green, organic solvents (ethanol, 2-propanol, ethylene glycol, and polyethylene glycol 200). The investigated sorbents are a supported ionic liquid phase (SILP) betainium sulfonyl(trifluoromethanesulfonylimide) poly(styrene-co-divinylbenzene) [Hbet-STFSI-PS-DVB], bare silica $\left(\mathrm{SiO}_{2}\right)$ and silica modified with ethylene diaminotetraacetic acid $\left(\mathrm{SiO}_{2}-\mathrm{TMS}-\right.$ EDTA) (Figure 1). The SILP has been previously used to recover scandium from $\mathrm{BR}$ leachate with nitric acid. ${ }^{17}$
Scandium was selectively eluted from the SILP column with dilute phosphoric acid, but the uptake of other major components of the BR leachate was also significant, which diminished the amount of leachate that could be processed. Therefore, an improvement in selectivity of the SILP by a solvometallurgical method is further investigated. Bare silica as sorbent can recover scandium from aqueous solutions, but it lacks selectivity in the presence of major elements of $\mathrm{BR}$, like iron and aluminum. ${ }^{27} \mathrm{SiO}_{2}$-TMS-EDTA had been investigated for the separation of light and heavy rare earths. ${ }^{28}$ However, its potential for scandium recovery from BR has not been exploited by solvometallurgical methods yet. The most promising combination of solvent and sorbent for scandium separation in batch sorption studies is then evaluated by studies on a real BR leachate in a column chromatography setup.

\section{EXPERIMENTAL SECTION}

Chemicals. Nitric acid (65\%), standard solutions (1000 $\mu \mathrm{g}$ $\mathrm{mL}^{-1}$ ) of scandium, yttrium, holmium, sodium, calcium, iron, aluminum, titanium, and silicon were purchased from ChemLab NV (Zedelgem, Belgium). Anhydrous iron(III) chloride (98\%), hydrochloric acid (37\%), ethanol (99.5\%, EtOH), 2propanol (99.7\%, i-Pr), ethylene glycol (99.5\% EG), polyethylene glycol (average molecular weight 200, PEG-200), methanol (HPLC grade), betaine hydrochloride (99\%), and triethylamine (99\%) were purchased from Acros Organics (Geel, Belgium). Silica $(0.015-0.040 \mathrm{~mm})$ was purchased from Merck (Overijse, Belgium). Polystyrene-divinylbenzene (PS-DVB) sulfonyl chloride resin (0.91 mmol g ${ }^{-1}, 200-400$ mesh) was purchased from RappPolymere (Tübingen, Germany). Trifluoromethanesulfonamide (98\%) was purchased from J\&K Scientific GmbH (Pforzheim, Germany). Dichloromethane (DCM) (p.a.), and acetone (p.a.) were purchased from Fisher Chemical (Loughborough, U.K.). N[(3-trimethoxysilyl)propyl] ethylenediamine triacetic acid trisodium salt (TMS-EDTA) (45 wt \%) was purchased from ABCR chemicals (Karlsruhe, Germany). Phosphoric acid (85\%) was purchased from Ashland Chemicals (Columbus, OH U.S.A.). Scandium(III) oxide (99.99\%) was kindly provided by Solvay (La Rochelle, France). Hydrated scandium(III) chloride was prepared by dissolving scandium(III) oxide in concentrated hydrochloric acid and evaporating until dryness. The chemicals were used as received without any further purification. A sample of BR was kindly provided by Aluminum of Greece (Agios Nikolaos, Greece).

Equipment. Batch sorption and leaching experiments were performed using a Thermo Fisher shaker (Type 462-0355). A fraction collector CF-2 (Spectrum Laboratories, Inc.) equipped with a drop sensor and the IPC 8-channel peristaltic pump (ISMATEC) was used for sampling during the chromatography studies. Concentrations of elements in solutions were 

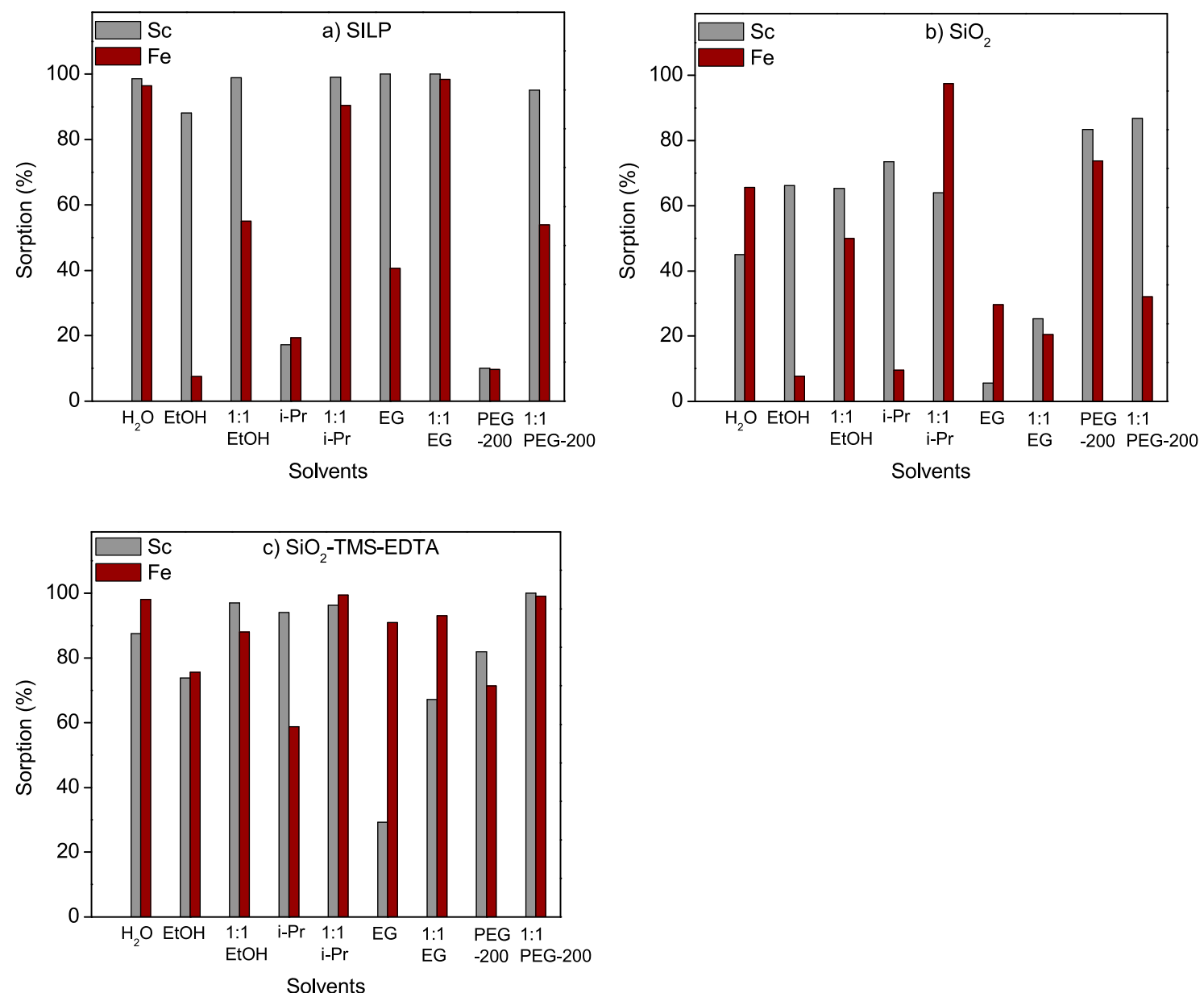

Figure 2. Sorption (\%) of scandium(III) and iron(III) from $2.5 \mathrm{~mL}$ of their $1 \mathrm{mmol} \mathrm{L} \mathrm{L}^{-1}$ aqueous, organic, and aqueous-organic mixtures of ethanol (EtOH), isopropanol (i-Pr), ethylene glycol (EG), and PEG-200 by $25 \mathrm{mg}$ of the sorbents: (a) SILP, (b) $\mathrm{SiO}_{2}$, and (c) SiO $2-\mathrm{TMS}-$ EDTA. The 1:1 ethanol, 1:1 isopropanol, and 1:1 PEG-200 are feeds comprising water and the solvent in 1:1 ratio.

measured by an inductively coupled plasma-optical emission spectrometer (ICP-OES) (PerkinElmer Avio 500) equipped with an axial/radial dual plasma view and GemCone High Solids nebulizer. The calibration solutions and all samples were prepared by dilution with 2 wt $\% \mathrm{HNO}_{3}$. Holmium (5 ppm) was used as an internal standard. X-ray powder diffraction (XRD) patterns of $\mathrm{BR}$ were collected from a $2 \theta$ angle of $5^{\circ}$ to $80^{\circ}$ in the Bragg-Brentano geometry on a Bruker D2 PHASER X-ray diffractometer equipped with a $\mathrm{CuK} \alpha$ radiation source operating at a voltage of $30 \mathrm{kV}$ and a current of $10 \mathrm{~mA}$. The raw data were processed with EVA software with the ICDD database. The SILP ( $100 \mathrm{mg})$ loaded with metals of the ethanolic leachate of $\mathrm{BR}$ and dried at $100{ }^{\circ} \mathrm{C}$ for $20 \mathrm{~min}$ was analyzed by a Bruker Vertex 70 Fourier transform infrared-attenuated total reflectance (ATR-FTIR), operating at room temperature. UV-vis absorption spectra of the bauxite residue leachates were measured with Agilent Cary 6000i spectrophotometer and Cary WinUV software. Lixiviants (0.7 mol L ${ }^{-1}$ in water or in ethanol) were used as blank reagents and for diluting the samples 900 times prior to analysis.

Batch Sorption Tests. Feed solutions of scandium and iron(III) were prepared by dissolving their chloride salts in water, ethanol, isopropanol, ethylene glycol or PEG-200. Synthetic binary feed solutions of scandium(III) and iron(III) with a concentration of $1 \mathrm{mmol} \mathrm{L}{ }^{-1}$ of each element were made by appropriate dilutions with water or an organic solvent.
In addition, the same binary solutions were prepared by dilution in organic solvents with water in 1:1 volume ratio. The SILP, [Hbet-STFSI-PS-DVB], and $\mathrm{SiO}_{2}-\mathrm{TMS}-\mathrm{EDTA}$ were synthesized according to previously reported procedures. $^{28,29}$ The sorbents were then dried in a vacuum oven for $4 \mathrm{~h}$ at $40{ }^{\circ} \mathrm{C}$. Typically, $25 \mathrm{mg}$ of these sorbents or of unmodified silica $\left(\mathrm{SiO}_{2}\right)$ was weighed in a $4 \mathrm{~mL}$ glass vial. Then, $2.5 \mathrm{~mL}$ of the synthetic binary feed of scandium(III) and iron(III) with a concentration of $1 \mathrm{mmol} \mathrm{L}^{-1}$ of each element was added. The samples were shaken for $4 \mathrm{~h}$ at room temperature and $250 \mathrm{rpm}$. Subsequently, the samples were filtered through a syringe filter with a $0.20 \mu \mathrm{m}$ pore size. The filtrate was then diluted to an appropriate concentration with 2 wt $\% \mathrm{HNO}_{3}$ prior to ICP-OES analysis. The amount of metal ions sorbed on the sorbents was calculated by using the following equation

$$
\text { Sorption }(\%)=\frac{\left(c_{\text {ini }}-c_{\mathrm{eq}}\right) \times 100}{c_{\text {ini }}}
$$

The initial metal ion concentration in the solution is $c_{\text {ini }}(\mathrm{mmol}$ $\mathrm{L}^{-1}$ ) and the equilibrium concentration of metal ions in the solution is $c_{\mathrm{eq}}\left(\mathrm{mmol} \mathrm{L}^{-1}\right)$.

Leaching of Bauxite Residue (BR). The BR was air-dried for $24 \mathrm{~h}$ at $105{ }^{\circ} \mathrm{C}$. An amount of $20.0 \mathrm{~mL}$ of $0.7 \mathrm{~mol} \mathrm{~L}^{-1} \mathrm{HCl}$ in water or in ethanol was added to $2.00 \mathrm{~g}$ of BR. The mixture was shaken for $24 \mathrm{~h}$ on the Thermo Fisher shaker at $250 \mathrm{rpm}$ 
at room temperature. The samples were filtered through a 0.20 $\mu \mathrm{m}$ pore size syringe filter and the freshly prepared leachates were used for column chromatography experiments.

Column Chromatography Tests. A gravity flow glass column (BIO-RAD) of $30 \mathrm{~cm}$ length and $0.7 \mathrm{~cm}$ diameter was used in chromatography separation experiments. The column was packed with $2 \mathrm{~g}$ of SILP by a wet packing method. The SILP was preconditioned with $0.01 \mathrm{~mol} \mathrm{~L}^{-1} \mathrm{HCl}$ solution or with absolute ethanol prior to each experiment. All column chromatography experiments were conducted at room temperature. For breakthrough curve experiments, $30 \mathrm{~mL}$ of leachate of $\mathrm{BR}$ with $0.7 \mathrm{~mol} \mathrm{~L}^{-1} \mathrm{HCl}$ in water or in ethanol was pumped through the column. In order to avoid significant evaporation of ethanolic samples, their containers were sealed right after they were collected. The concentration of elements in the collected fractions was measured by the ICP-OES. The breakthrough percentage of $\mathrm{BR}$ components was calculated from the ratio of their concentrations in the collected fractions $\left(c, \mathrm{mg} \mathrm{L}^{-1}\right)$ and the concentration of the elements in the feed $\left(c_{0}, \mathrm{mg} \mathrm{L}^{-1}\right)$.

For the optimization of scandium separation by elution, 1 $\mathrm{mL}$ of the aqueous or ethanolic leachate was applied on the column with the SILP. For scandium separation from the aqueous leachate, $9 \mathrm{~mL}$ of $0.1 \mathrm{~mol} \mathrm{~L}^{-1} \mathrm{HCl}$ was then pumped through the column. For the separation from the ethanolic leachate, $9 \mathrm{~mL}$ of ethanol was used. The recovery of elements by the SILP was calculated using the following formula

$$
\text { Recovery by the SILP }(\%)=\frac{\left(m_{0}-m_{\mathrm{eq}}\right) \times 100}{m_{0}}
$$

The mass of elements $(\mathrm{mg})$ in $1 \mathrm{~mL}$ of the feed is $m_{0}$, and the mass of elements in the collected fractions $(\mathrm{mg})$ is $m_{\text {eq }}$ calculated from the measured mass concentrations.

To remove possible impurities in sample tubes, $10 \mathrm{~mL}$ of 0.1 $\mathrm{mol} \mathrm{L}{ }^{-1} \mathrm{HCl}$ in water was pumped through the column prior to an eluent for the separation of scandium. The elution of the sorbed metals was then performed with $70 \mathrm{~mL}$ of $0.1 \mathrm{~mol} \mathrm{~L}^{-1}$ $\mathrm{H}_{3} \mathrm{PO}_{4}$ in water, followed by $40 \mathrm{~mL}$ of $2 \mathrm{~mol} \mathrm{~L}^{-1} \mathrm{HCl}$ in water. Flow rates of the leachates were set at $0.1 \mathrm{~mL} \mathrm{~min}^{-1}$ and of the eluents at $0.5 \mathrm{~mL} \mathrm{~min}^{-1}$. From the measured concentration of elements in the collected fractions, the elution percentage was calculated by using the following formula

$$
\text { Elution }(\%)=\sum_{n} \frac{m_{n} \times 100}{m_{0}}
$$

The mass of elements in the collected fractions is $m_{n}$, which is calculated from the measured mass concentration, whereas $m_{0}$ is the mass of elements $(\mathrm{mg})$ in $1 \mathrm{~mL}$ of the feed.

\section{RESULTS AND DISCUSSION}

Selectivity of Sorbents in Organic Solutions Tested in Batch Experiments. The intrinsic selectivity of a sorbent for a given metal ion is influenced by several factors: (a) the mechanism of sorption, which is typically governed by the functional groups of sorbents, the coordination sphere, and the charge of metal ions, (b) the kinetics of the sorption, and (c) the sorption medium, including the presence of metal complexing agents. Here, the selectivity of the three sorbents (SILP, $\mathrm{SiO}_{2}$, and the $\mathrm{SiO}_{2}$-TMS-EDTA) was explored by variation of the sorption medium. The selective uptake of scandium was investigated from water, ethanol, isopropanol, ethylene glycol, and PEG-200 solutions containing scandium and iron in equimolar concentrations. In previous ionexchange studies, it has been pointed out that scandium(III) and iron(III) separation from BR leachates is challenging because of the similar charge density of these ions and their similar hydration enthalpies. ${ }^{18}$ As it is also one of the major elements in the leachate of $\mathrm{BR}$, iron was chosen for the sorption studies as a competitive ion to scandium.

Both scandium and iron were nearly quantitatively sorbed by the SILP from their binary aqueous feed (Figure 2a). However, about $88 \%$ of scandium was recovered from the ethanolic feed by the SILP with a negligible amount of cosorbed iron. Moreover, the sorption of scandium was still higher (98\%) than the sorption of iron (55\%) even from the feed comprising ethanol and water in 1:1 volume ratio. The recovery of scandium and iron by the SILP takes place by exchange of their positively charged species in the feed for protons of the carboxyl-group of the SILP. ${ }^{29}$ In aqueous acidic solutions of $\mathrm{ScCl}_{3}$ of concentration below $0.255 \mathrm{~mol} \mathrm{~L}^{-1}$, scandium is predominantly present as hexaaqua complex $\left[\mathrm{Sc}\left(\mathrm{H}_{2} \mathrm{O}\right)_{6}\right]^{3+}$. Neutral or anionic species like $\mathrm{ScCl}_{3},\left[\mathrm{ScCl}_{4}\right]^{-}$, or $\left[\mathrm{ScCl}_{6}\right]^{3-}$ are not formed, even in the presence of an excess of chloride ions. ${ }^{30}$ Therefore, in the tested $1 \mathrm{mmol} \mathrm{L}^{-1}$ aqueous feed, scandium(III) is present as $\left[\mathrm{Sc}\left(\mathrm{H}_{2} \mathrm{O}\right)_{6}\right]^{3+}$ which is exchanged with the protons of the SILP. The speciation of iron(III) in aqueous solutions is more diverse, and the most common complexes in acidic chloride solutions are octahedral hexaaqua complex $\left[\mathrm{Fe}\left(\mathrm{H}_{2} \mathrm{O}\right)_{6}\right]^{3+}$, pentaaquahydroxy complex $[\mathrm{Fe}-$ $\left.\left(\mathrm{H}_{2} \mathrm{O}\right)_{5} \mathrm{OH}\right]^{2+}$, tetraaquadihydroxy complex [Fe$\left.\left(\mathrm{H}_{2} \mathrm{O}\right)_{4}(\mathrm{OH})_{2}\right]^{+}$, monochloro complex $\left[\mathrm{Fe}\left(\mathrm{H}_{2} \mathrm{O}\right)_{5} \mathrm{Cl}\right]^{2+}$, dichloro complex trans- $\left[\mathrm{Fe}\left(\mathrm{H}_{2} \mathrm{O}\right)_{4} \mathrm{Cl}_{2}\right]^{+}$, trichloro complex $\left[\mathrm{Fe}\left(\mathrm{H}_{2} \mathrm{O}\right)_{3} \mathrm{Cl}_{3}\right]$ and tetrahedral tetrachloro complex $\left[\mathrm{FeCl}_{4}\right]^{-31-34}$ In the tested aqueous feed with $1 \mathrm{mmol} \mathrm{L}^{-1}$ iron(III) and an initial $\mathrm{pH}$ of 2.67, $\left[\mathrm{Fe}\left(\mathrm{H}_{2} \mathrm{O}\right)_{6}\right]^{3+}$ and $\left[\mathrm{Fe}\left(\mathrm{H}_{2} \mathrm{O}\right)_{5} \mathrm{OH}\right]^{2+}$ are the dominant species. ${ }^{34}$ These cationic species can also be exchanged with the protons of the SILP. Iron complexes with higher chloride-to-metal ratios are unlikely to be recovered by carboxyl groups of the SILP but are not expected to occur in the investigated aqueous solutions either, as these species are formed at high chloride concentrations or at high temperatures in aqueous conditions. In the present study, the feed was prepared by dissolving $\mathrm{ScCl}_{3}$ and $\mathrm{FeCl}_{3}$ in the tested solvents, resulting in a total chloride concentration of only $6 \mathrm{mmol} \mathrm{L}^{-1}$. Literature results suggest that in ethanol solutions the formation of high order chloro complexes may take place even at low chloride concentration (e.g., $\left.10^{-2} \mathrm{~mol} \mathrm{~L}^{-1}\right){ }^{35}$ As the neutral or negatively charged chloro complexes are unlikely to be recovered by the SILP, their formation could explain the selectivity of the SILP for scandium over iron from the feeds with ethanol. The formation of chloro complexes in ethanol solutions at low chloride concentration is not limited to iron, and it was also reported in a study on purification of ${ }^{68} \mathrm{Ga}$ from $\mathrm{HCl}$-ethanol mixtures by an anion exchange resin. ${ }^{36}$

Scandium was preferentially sorbed over iron by the SILP from ethylene glycol feed (Figure 2a) as well. However, from the water-ethylene glycol feed, scandium and iron were equally sorbed and the selectivity was lost. The sorption of both metals by the SILP from the isopropanol and PEG-200 feeds was less than 20\%. Low swelling of the SILP in the solvents which could render functional groups inaccessible could have affected the uptake of the metal ions. However, this was not further investigated, as the separation of the two metals was not achieved. The SILP exhibited higher sorption 
of scandium over iron from the water-PEG-200 feed. Iron forms complexes with PEG in solutions with water in 1:1 volume ratio, which could have led to its poor uptake by the SILP. ${ }^{37}$

Silica exhibited $20 \%$ higher sorption of iron over scandium from the aqueous feed (Figure $2 b$ ). By changing the feed from aqueous to ethanol or isopropanol feed, the selectivity of silica was reversed. Scandium was preferentially sorbed $(66 \%$ and $74 \%$ for ethanol and isopropanol, respectively) with less than $10 \%$ of iron. However, the selectivity of silica for scandium from the water-ethanol feed was significantly reduced, accompanied by an increase in iron sorption up to $50 \%$. Moreover, the selectivity of the silica for scandium was completely lost in the case of the water-isopropanol feed. The silanol groups $(-\mathrm{SiOH})$ of the hydrated silica are weakly acidic. Therefore, the selectivity of the silica for scandium over iron from pure ethanol can be explained based on the formation of iron(III) chloro complexes (vide supra). The loss of selectivity of silica in water-ethanol and water-isopropanol mixtures can be attributed to an intrinsically higher preference of silica for iron in aqueous feeds and to its low sorption capacity. Conversely, a significant selectivity for scandium was not achieved from the feed with PEG-200, while a certain degree of selectivity was observed from the water-PEG-200 feed. It is known that PEG can coordinate cations. ${ }^{38} \mathrm{Ab}$ initio calculations in previous studies suggest that water has a strong influence on the cation selectivity of PEG-200. ${ }^{39}$ For instance, the bond in metal-PEG complexes is significantly stronger in the presence of water than in a gas phase. ${ }^{39}$ Better selectivity of $\mathrm{SiO}_{2}$ for scandium from the water-PEG-200 feed versus the selectivity from the PEG-200 feed validates the influence of water on the speciation of metals in the feed and their selective sorption. However, PEG-200-ion and PEG-200-water interactions have not been completely elucidated yet, despite the long history of studies on the behavior of PEG-200 in solution.

The $\mathrm{SiO}_{2}-\mathrm{TMS}-\mathrm{EDTA}$ sorbent exhibited higher total sorption capacity of both scandium and iron than nonfunctionalized silica (Figure 2c). However, iron was preferentially recovered from all tested feeds with the exception of isopropanol feed. Still, scandium and iron were equally recovered by the $\mathrm{SiO}_{2}$-TMS-EDTA from water-isopropanol feed. The EDTA is a chelating functional group with six donor atoms (four oxygen and two nitrogen atoms) (Figure 1). EDTA can form very stable chelates with metal ions. The stability constants ( $\log K$ values) for complexes formed between EDTA and scandium(III) and iron(III) in the aqueous solutions are 23.1 and 25.1, respectively, which explains the preferential uptake of iron(III) over scandium(III) from aqueous solutions. ${ }^{21}$ In contrast, the $\log K$ values of common positively charged iron(III) complexes in chloride aqueous solutions are -2.2 for $\left[\mathrm{Fe}\left(\mathrm{H}_{2} \mathrm{O}\right)_{5} \mathrm{OH}\right]^{2+}$, from -4.6 to -3.5 for $\left[\mathrm{Fe}\left(\mathrm{H}_{2} \mathrm{O}\right)_{4}(\mathrm{OH})_{2}\right]^{+}, 1.5-1.9$ for $\left[\mathrm{Fe}\left(\mathrm{H}_{2} \mathrm{O}\right)_{5} \mathrm{Cl}\right]^{2+}$, and $13-15$ for $\left[\mathrm{Fe}\left(\mathrm{H}_{2} \mathrm{O}\right)_{4} \mathrm{Cl}_{2}\right]^{+}{ }^{40,41}$ Very few $\log \mathrm{K}$ values of iron(III) complexes in nonaqueous media have been reported in the literature. Still, the high uptake of iron(III) from nonaqueous solutions by the $\mathrm{SiO}_{2}-\mathrm{TMS}-\mathrm{EDTA}$ indicates that the complexes with EDTA are also more stable than the iron(III) complexes in the nonaqueous feeds (Figure 2). Hence, a selective recovery of scandium was not achieved with $\mathrm{SiO}_{2}-\mathrm{TMS}-$ EDTA.

From the batch sorption studies it was concluded that the separation of scandium and iron by the SILP from the ethanol solution is the most efficient (Figure 2). The separation of the two metals was effective even in the presence of water. This robustness of the method under high water content (aqueousto-organic solvent ratio of 1:1) simplifies the separation process as the content of water does not have to be precisely controlled. For instance, dilution of concentrated aqueous lixiviants (e.g., concentrated $\mathrm{HCl}$ ) by ethanol for leaching of scandium from its resources like $B R$ is straightforward. Therefore, the separation of scandium from ethanolic leachate of BR was further explored.

Leaching of Bauxite Residue and Its Characterization. Leaching of scandium from BR has been studied extensively, including room-temperature acid leaching, dry digestion and multistage leaching, selective roasting prior to leaching with mineral acids, leaching with a functionalized ionic liquid, and so forth. ${ }^{11,42-47}$ As the focus of the present study is on the chromatography separation of scandium, simple hydro- and solvometallurgical leachings of the Greek BR was performed at room temperature. ${ }^{14}$ The recovery of yttrium was studied among other minor components of the BR, as the previous studies showed that the rare earths (e.g., neodymium and dysprosium) exhibit similar behavior in the SILP column chromatography to yttrium. ${ }^{17}$ The concentrations of scandium and yttrium in the BR leachates were very similar regardless whether the leaching was performed by $0.7 \mathrm{~mol} \mathrm{~L}^{-1} \mathrm{HCl}$ in water or $0.7 \mathrm{~mol} \mathrm{~L}^{-1} \mathrm{HCl}$ in ethanol (Figure 3a, Table S1). The most prominent difference in the elemental composition in the two leachates was in sodium concentration (Figure 3b, Table $\mathrm{S} 1$ ). $\mathrm{NaCl}$ is formed by leaching of $\mathrm{BR}$ with $\mathrm{HCl}$ solution. The solubility of $\mathrm{NaCl}$ at $25{ }^{\circ} \mathrm{C}$ in water is about 357 $\mathrm{g} \mathrm{L}^{-1}$, and in ethanol it is no more than about $0.5 \mathrm{~g} \mathrm{~L}^{-1}$. Therefore, the vast majority of the formed $\mathrm{NaCl}$ remained in the solid reside after leaching with $0.7 \mathrm{~mol} \mathrm{~L}^{-1} \mathrm{HCl}$ in ethanol. The X-ray diffractograms of the solid residues confirmed the presence of $\mathrm{NaCl}$ (Figure 4). The diffractions of $\mathrm{NaCl}$ were not observed in the XRD patterns of the solid residue after leaching with $0.7 \mathrm{~mol} \mathrm{~L}^{-1} \mathrm{HCl}$ in water, nor of the untreated BR (Figure 4). The lesser codissolution of sodium by leaching with $0.7 \mathrm{~mol} \mathrm{~L}^{-1} \mathrm{HCl}$ in ethanol can facilitate the downstream processing of the leachate for scandium recovery, as sodium could interfere in ion exchange process by the SILP.

It is well-known that silicic acid, which is a precursor for silica gel, is formed in aqueous $\mathrm{HCl}$ leachates of $\mathrm{BR}{ }^{43}$ Silica gel formation is a serious drawback in the recovery of scandium from BR by hydrometallurgical methods as it can reduce leaching kinetics and make filtration very difficult. Several studies have been performed to diminish the silica gel formation: (a) a combination of sulfation, roasting, and leaching processes, ${ }^{40}$ (b) dry digestion by concentrated $\mathrm{H}_{2} \mathrm{SO}_{4}$ or $\mathrm{HCl}$, followed by water leaching, ${ }^{47}$ and (c) oxidative leaching by of $\mathrm{H}_{2} \mathrm{O}_{2}$ and $\mathrm{H}_{2} \mathrm{SO}_{4}$ at $90{ }^{\circ} \mathrm{C}$. ${ }^{48-50}$ In the present study, ethanol in the ethanolic leachates of $\mathrm{BR}$ acts as a solubilizing agent for silicic acid and reduces its polymerization and thus the silica gel formation. ${ }^{51}$ The formed silica gel in the aqueous leachate of $\mathrm{BR}$ and its absence in the ethanolic leachate could also be visually observed in the aged BR leachates ( $>4$ months) (Figure S1). Hence the drawback of silica gel formation is greatly circumvented by the solvoleaching of BR under milder conditions than in the abovementioned pyrometallurgical and hydrometallurgical processes.

Breakthrough Curves with Bauxite Residue Leachates. In order to evaluate the selectivity of the SILP for scandium from the aqueous and ethanolic leachates of BR 


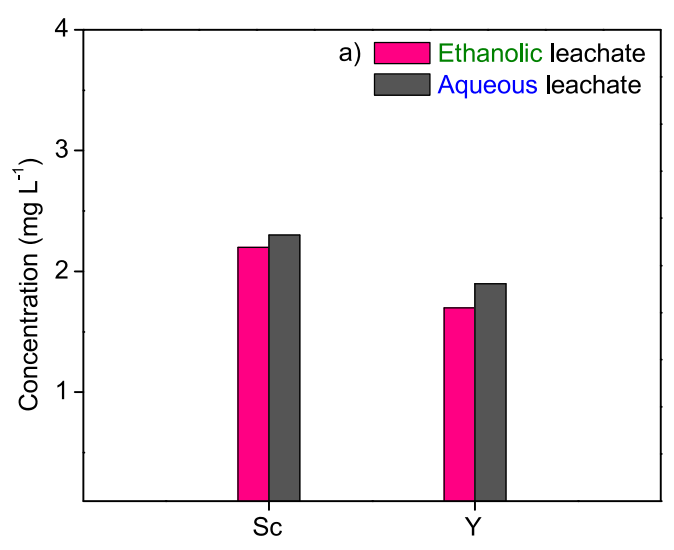

Minor elements in the leachates

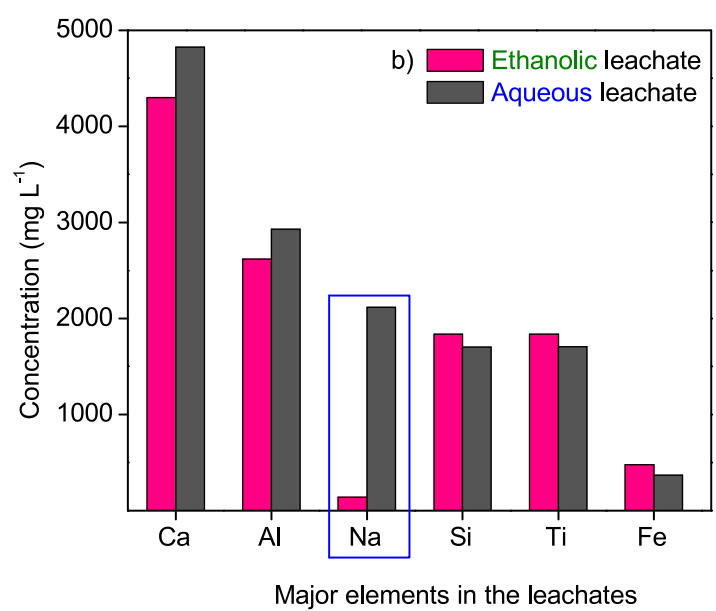

Figure 3. Concentrations $\left(\mathrm{mg} \mathrm{L}^{-1}\right)$ of elements in the leachates of the Greek BR: (a) minor elements (scandium and yttrium) and (b) major elements (calcium, aluminum, sodium, silicon, titanium, and iron). The BR was leached with $0.7 \mathrm{~mol} \mathrm{~L}^{-1} \mathrm{HCl}$ in water (aqueous leachate) or $0.7 \mathrm{~mol} \mathrm{~L}^{-1} \mathrm{HCl}$ in ethanol (ethanolic leachate) at room temperature and with a liquid-to-solid ratio $(\mathrm{L} / \mathrm{S})$ of 10 .

under flow, breakthrough curve experiments were performed. The leachates of BR were pumped through the column until equilibrium concentration of elements was equal to their initial concentration, that is, until all elements reached a complete breakthrough. The sorption preference of the SILP was estimated from the ratio of equilibrium and initial concentrations of elements and the volume of the leachate required to reach the breakthrough.

The sorption sequence of elements in the aqueous leachate was in the following order: $\mathrm{Si} \approx \mathrm{Ti}<\mathrm{Na}<\mathrm{Ca} \approx \mathrm{Fe} \approx \mathrm{Al}<\mathrm{Sc}$ $<\mathrm{Y}$ (Figure 5a). The high preference of the SILP for scandium and yttrium is in accordance with the previous breakthrough curve studies on synthetic aqueous solutions composed of dissolved nitrate salts of major and minor elements of BR. ${ }^{17}$ Electrostatic interactions of the trivalent rare-earth ions and their hydration enthalpies were found to be the dominant factors for the selectivity of the SILP for the rare earths over major components in $\mathrm{BR} .^{17}$ In the aqueous leachate of $\mathrm{BR}$ with $\mathrm{HCl}$, containing relatively low chloride concentrations, the metals are present as hydrated metal ions, and the sorption mechanism is analogous to that in nitrate media.

In the previous study on recovery of scandium by the SILP, the exchange between protons of the carboxylic acid group of the SILP and scandium ions was confirmed by the FTIR study. ${ }^{29}$ The absorption band that corresponds to the carboxylic group of the SILP (around $1750 \mathrm{~cm}^{-1}$ ) had shifted to a lower wavenumber $\left(1649 \mathrm{~cm}^{-1}\right)$ after scandium recovery due to the presence of the deprotonated carboxylate. A similar shift of the absorption band was observed in the FTIR spectra of the dry SILP after recovery of metals from the ethanolic leachate of BR (Figure S2). The results indicate that the proton exchange mechanism is also taking place in the recovery of metal ions by the SILP from the ethanolic leachate of BR. The sorption sequence from the ethanolic leachate was $\mathrm{Si}<\mathrm{Fe} \approx \mathrm{Ti}<\mathrm{Sc}<\mathrm{Al}<\mathrm{Y}<\mathrm{Ca}<\mathrm{Na}$ (Figure 5b). Since silicon is present in the form of silicates in the BR (Figure 4), it is anticipated that oxyanions are the predominant species of silicon in the BR leachates, which are poorly retained by the SILP with carboxylic acid functional group. The sorption of iron from the ethanolic leachate was lower compared to that of the other metals, which can possibly be ascribed to its tendency to form chloro complexes in nonaqueous media. ${ }^{24}$ However, sodium and calcium were sorbed by the SILP more efficiently from the ethanolic leachate than the other elements

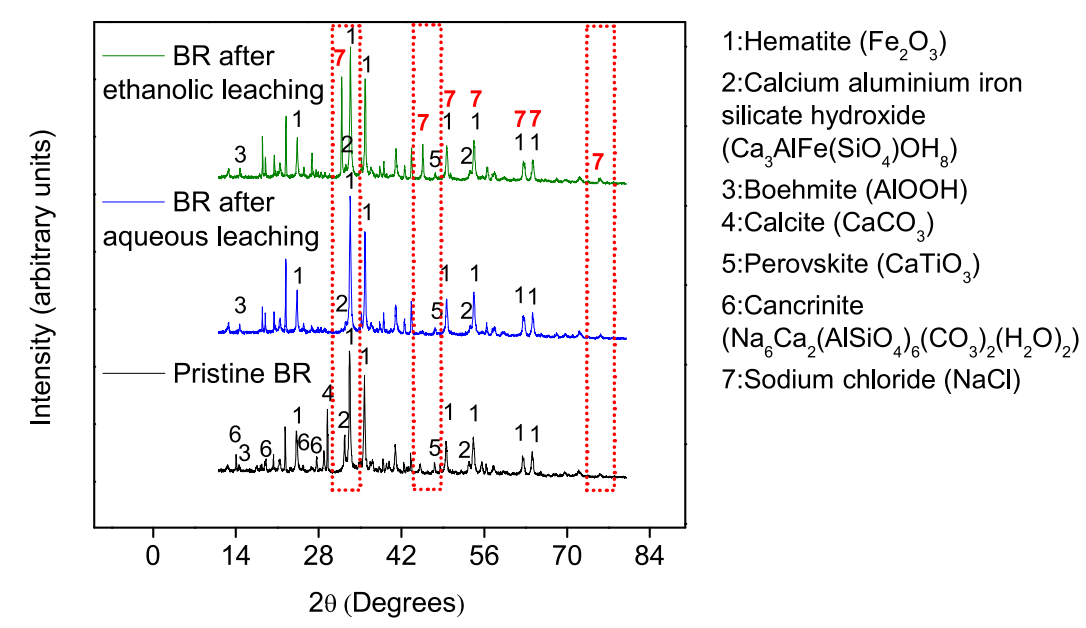

Figure 4. X-ray diffractograms of the Greek BR (pristine BR) and the solid residues after leaching with $0.7 \mathrm{~mol} \mathrm{~L}^{-1} \mathrm{HCl}$ in water (BR after aqueous leaching) or $0.7 \mathrm{~mol} \mathrm{~L}{ }^{-1} \mathrm{HCl}$ in ethanol ( $\mathrm{BR}$ after ethanolic leaching). The dotted red lines emphasize the particular reflections of $\mathrm{NaCl}$ in the diffractograms. 

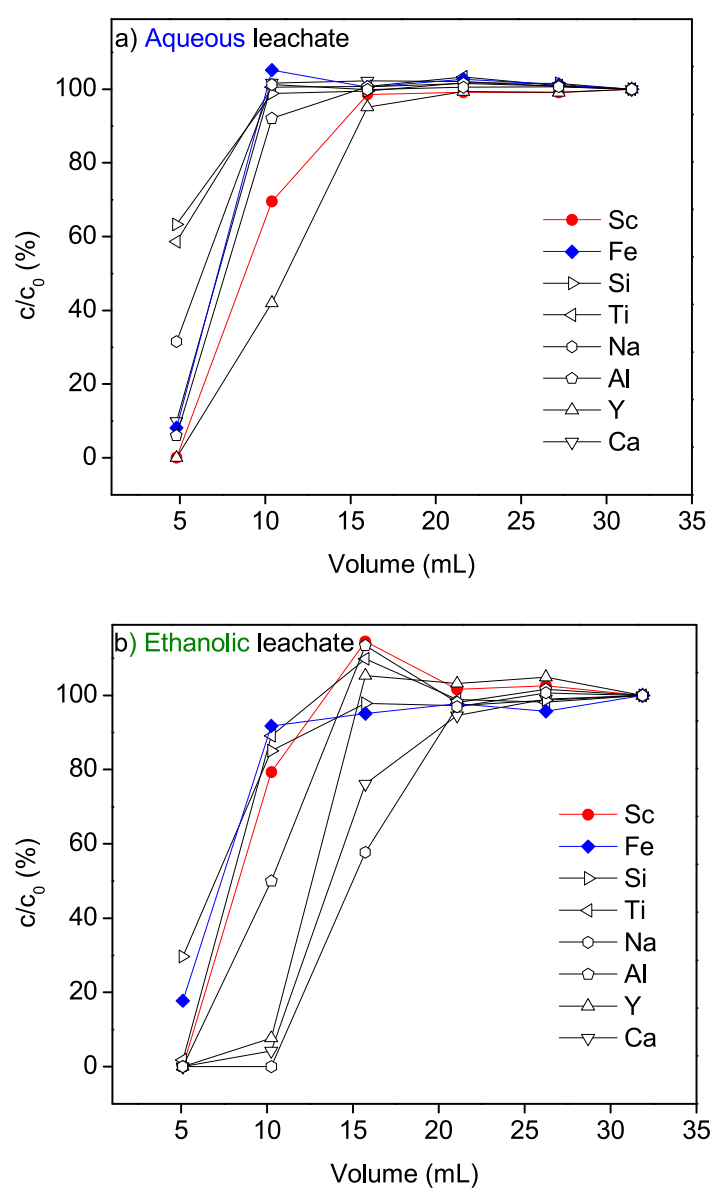

Figure 5. Breakthrough curves of BR leachates with (a) $0.7 \mathrm{~mol} \mathrm{~L}^{-1}$ $\mathrm{HCl}$ in water (aqueous leachate) or (b) $0.7 \mathrm{~mol} \mathrm{~L}^{-1} \mathrm{HCl}$ in ethanol (ethanolic leachate) by $2 \mathrm{~g}$ of the SILP. The flow rate was $0.1 \mathrm{~mL}$ $\min ^{-1}$.

which is opposite to the sorption preference of the SILP from the aqueous leachate (Figure 5). Generally, in aqueousorganic solutions, such as the ethanolic leachate of $\mathrm{BR}$, the solvation of cations is different compared to aqueous solutions. The organic solvent can decrease the forces binding the first hydration shell and decrease the size of the outer hydration cloud and thus reduce the concentration of water molecules around the cations. ${ }^{24,52}$ One consequence of this is that the anionic chloro complexes can form at lower concentrations of $\mathrm{HCl}$, as in the case of iron(III), and the differences in tendencies to form chloro complexes are generally enhanced. Moreover, because the forces binding the hydration shell depend on the charge density of the cation they will decrease with an increase in the size of a cation. ${ }^{24}$ The release of the hydration shell will therefore take place more easily for the larger cations with lower charge density. As a result, the protons of a sorbent can preferentially exchange with cations of lower charge density, like sodium and calcium. This partly clarifies the uptake preference of the metals by the SILP from the ethanolic leachate.

Although sodium was the most favorably recovered element from the ethanolic leachate, its concentration in the ethanolic leachate was significantly lower than in the aqueous leachate (Figure 3). Thus, the uptake of sodium from the ethanolic leachate has a limited impact on the efficiency of the SILP for scandium recovery. However, the high concentrations of aluminum in the leachate of $\mathrm{BR}$, exceeding that of scandium by a factor of 1000 , did result in diminished scandium binding due to competition for the available sorption sites (Figure 3 and Figure 5). Still, aluminum can be recovered beforehand from the BR, for instance, by sintering processes. ${ }^{53,54}$ Several factors can have an impact on the selectivity of the sorption process from the mixture of aqueous-organic solvents, apart from the solvation and the formation of negatively charged complexes. They include the strength of the cation-organic solvent interactions, hydrogen bonding, the dielectric constant of the medium, and the standard molar free energies of transfer of single cations between different media. ${ }^{55-57}$ Conceptually, it is difficult to concurrently consider all these factors and to quantify their effect on the sorption of metals from the ethanolic leachate of BR by the SILP. However, their overall effect is reflected in the uptake sequence of the elements from the ethanolic leachate.

The breakthrough point $\left(c / c_{0}=100 \%\right)$ for scandium and yttrium was achieved after approximately $15 \mathrm{~mL}$ of either aqueous or ethanolic leachate was flowed through the column packed with $2 \mathrm{~g}$ of the SILP. The tested leachates were obtained from the BR without any prior treatment to remove the major elements. Under these conditions, a higher sample throughput was not achieved regardless of the lixiviant due to the competition in sorption of scandium and yttrium with major elements and protons of the acidic leachates. However, several studies have been performed to recover major components of the $\mathrm{BR}^{10,53}$ Our results highlight the importance of the nature of lixiviants for designing an integrated process for metal recovery from the BR. It has been shown that the selectivity of the SILP is greatly affected by the solvent (water or ethanol). On one hand, the uptake of iron is diminished from ethanolic leachates in comparison to other elements and its uptake from aqueous leachate. On the other hand, the uptake of highly concentrated calcium and aluminum is enhanced from the ethanolic leachate with respect to the aqueous leachate. Therefore, depending on the pretreatment methods applied to BR for the recovery of major components, either an aqueous or ethanolic lixiviant may be beneficial to the subsequent recovery of scandium by the SILP.

Separation of Scandium from Bauxite Residue Leachate by Elution Column Chromatography. A complete selectivity in sorption of only scandium from a complex matrix such as the BR leachate was not achieved by tuning the solvent in which the metals are dissolved (water or ethanol). Therefore, a column chromatography separation of scandium from the aqueous and ethanolic leachate was performed by selective elution of the elements recovered by the SILP.

The recovery of elements by the SILP from $1 \mathrm{~mL}$ of the leachates and after eluting the column with $9 \mathrm{~mL}$ of $0.01 \mathrm{~mol}$ $\mathrm{L}^{-1} \mathrm{HCl}$ (after aqueous leachate) or with absolute ethanol (after ethanolic leachate) was assessed (Figure 6 and Figure 7). Scandium and yttrium were quantitatively recovered from both leachates along with sodium, aluminum, and calcium (Figure 6). Titanium recovery was enhanced from the ethanolic leachate in comparison to its recovery from the aqueous leachate. Silicon recovery was negligible from both leachates. Since it can be anticipated that silicon in the leachates is present mainly in the anionic form (vide supra), its low recovery by the SILP can mainly be ascribed to its weak sorption. Iron was quantitatively recovered from the aqueous leachate of the BR after eluting the SILP with $0.01 \mathrm{~mol} \mathrm{~L}^{-1}$ 


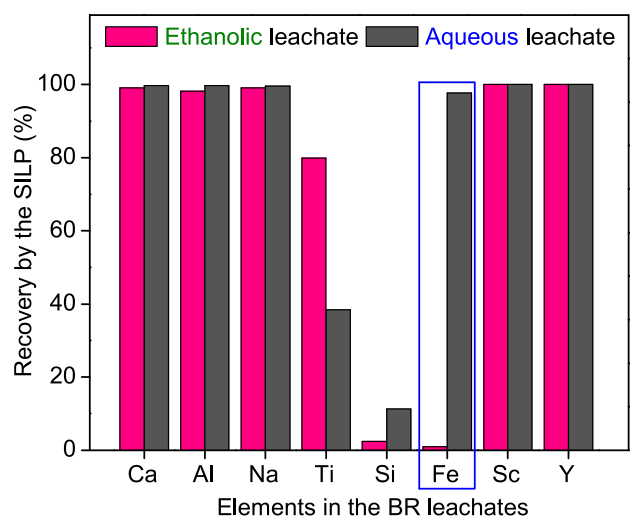

Figure 6. Recovery of elements by $2 \mathrm{~g}$ of the SILP from $1 \mathrm{~mL}$ of BR leachate with $0.7 \mathrm{~mol} \mathrm{~L}^{-1} \mathrm{HCl}$ in water (aqueous leachate) followed by elution with $9 \mathrm{~mL}$ of $0.1 \mathrm{~mol} \mathrm{~L}^{-1} \mathrm{HCl}$ in water, and from $1 \mathrm{~mL}$ of $\mathrm{BR}$ leachate with $0.7 \mathrm{~mol} \mathrm{~L}^{-1} \mathrm{HCl}$ in ethanol (ethanolic leachate), followed by elution with $9 \mathrm{~mL}$ of ethanol.
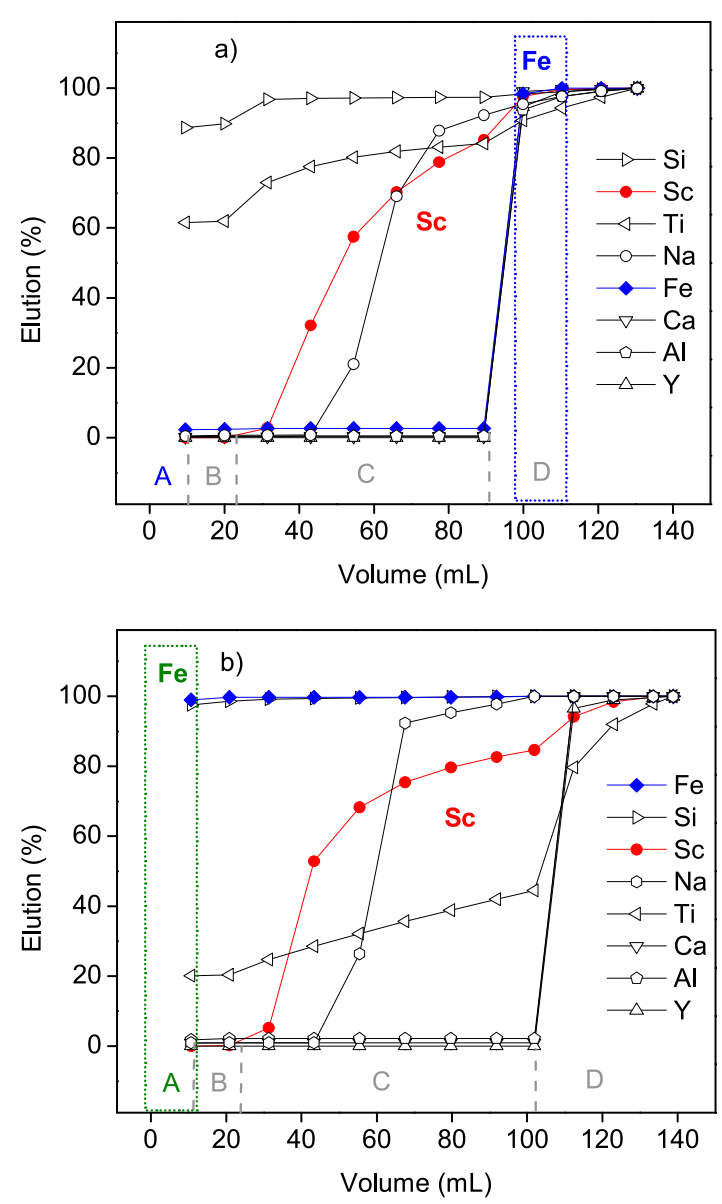

Figure 7. Chromatography separation of scandium $(\mathrm{Sc})$ from (a) aqueous or (b) ethanolic BR leachates. Mobile phases: (A) $1 \mathrm{~mL}$ of leachate of BR followed by $9 \mathrm{~mL}$ of $0.1 \mathrm{~mol} \mathrm{~L}^{-1} \mathrm{HCl}$ for aqueous leachate (a), or $9 \mathrm{~mL}$ of ethanol for ethanolic leachate (b); (B) 0.1 mol L-1 $\mathrm{HCl}$; (C) $0.1 \mathrm{~mol} \mathrm{~L}^{-1} \mathrm{H}_{3} \mathrm{PO}_{4}$; (D) $2 \mathrm{~mol} \mathrm{~L}^{-1} \mathrm{HCl}$. Flow rate of leachates was $0.1 \mathrm{~mL} \mathrm{~min}-1$ and of eluents was $0.5 \mathrm{~mL} \mathrm{~min}{ }^{-1}$. Dashed lines mark the volume of each mobile phase. Dotted lines mark the elution of iron $(\mathrm{Fe})$.

$\mathrm{HCl}$ (Figure 6 and Figure 7a). Conversely, iron was separated from the other elements of the ethanolic leachate of BR simply by elution of the SILP with ethanol (Figure $7 \mathrm{~b}$ ). As anticipated from the batch sorption and breakthrough studies, ethanol is a very efficient eluent for separating iron from the other components of the BR leachate.

Generally, iron separation from common minerals of the major base metals (e.g., $\mathrm{Cu}, \mathrm{Zn}, \mathrm{Ni}$, and $\mathrm{Co}$ ) is a major challenge in hydrometallurgy. ${ }^{58}$ The present study in which iron(III) is separated from the BR leachate using ethanol and the SILP demonstrates the potential of solvometallurgical methods for tuning flowsheets for metal recovery. On the basis of environmental impact and toxicity, ethanol is generally considered as a green solvent. ${ }^{59}$ It can be produced from biomass and is usually available in large quantities at a low price. $^{59,60}$ Therefore, apart from its performance ethanol is a sustainable solvent, which is the requirement for solvents used in solvometallugry.

After eluting the weakly bonded components of the BR from the SILP column with $0.01 \mathrm{~mol} \mathrm{~L}^{-1} \mathrm{HCl}$ or with ethanol, an additional $10 \mathrm{~mL}$ of $0.1 \mathrm{~mol} \mathrm{~L}^{-1}$ aqueous $\mathrm{HCl}$ was flowed through the column prior to further elution of the remaining metals (Figure 7). The bed height of the SILP which was previously eluted with ethanol decreased from approximately 12 to $9 \mathrm{~cm}$. This change in the bed height was not observed in SILP which was previously eluted with $0.01 \mathrm{~mol} \mathrm{~L}^{-1}$ aqueous $\mathrm{HCl}$. The polystyrene-based SILP is better solvated by ethanol than by water, thus it swells better in ethanol and the change from ethanolic eluent to the aqueous eluent essentially caused the changes in the bed height of the SILP. By eluting the columns with $10 \mathrm{~mL}$ of $0.1 \mathrm{~mol} \mathrm{~L}^{-1} \mathrm{HCl}$, the bed heights of both columns were leveled at approximately $9 \mathrm{~cm}$. Furthermore, this elution further purifies the column and the tubing from possible remaining contaminants of the complex BR leachates (other trace-metal impurities, organic matter, and so forth) prior to elution of scandium.

It has been demonstrated previously that scandium can be selectively eluted with $0.1 \mathrm{~mol} \mathrm{~L}^{-1} \mathrm{H}_{3} \mathrm{PO}_{4}$ from the SILP. ${ }^{17}$ Therefore, $0.1 \mathrm{~mol} \mathrm{~L}^{-1} \mathrm{H}_{3} \mathrm{PO}_{4}$ has been applied as eluent to separate scandium from other components recovered by the SILP from aqueous or ethanolic $\mathrm{HCl}$ leachates of the BR (Figure 7). About $84 \%$ of scandium was separated from the vast majority of other components of both aqueous and ethanolic leachate of BR. Still, sodium was eluted together with scandium. The concentration of sodium in the ethanolic leachate was significantly lower than in the aqueous leachate (Figure 3, Table S1). As a result, the sodium content was lower in the fractions collected after scandium separation from the ethanolic leachate than from the aqueous leachate.

After scandium was separated by elution, the column was regenerated with $2 \mathrm{~mol} \mathrm{~L}^{-1} \mathrm{HCl}$ (Figure 7). The column effluent after elution of the remaining components of the aqueous leachate of BR was mainly composed of a mixture of the major elements, namely iron, aluminum, and calcium (Figure 7a). Silicon and the majority of titanium were separated from other elements in the first fractions. The mixture of silicon and titanium can be used, for instance, in the synthesis of titanium silicate materials for catalysis and adsorptive separations. ${ }^{61}$ By elution of the remaining components of the ethanolic leachate of BR (Figure 7b), titanium was collected in fractions together with aluminum and calcium. Their mixture can be considered as a potential precursor of a $\mathrm{CaO}-\mathrm{Al}_{2} \mathrm{O}_{3}-\mathrm{TiO}_{2}$ slag for steel refining. ${ }^{62}$ Moreover, their fractions were free from iron, as iron was eluted with ethanol in the initial fraction, along with silicon. The iron-silicate fraction could be considered as a resource for 
abrasives for blast cleaning. Another potential application is in the production of $\mathrm{FeCl}_{3}$, which is used for wastewater treatment and in the production of printed circuit boards. ${ }^{63}$ Yttrium was eluted with $2 \mathrm{~mol} \mathrm{~L}^{-1} \mathrm{HCl}$ along with the major components of both aqueous and ethanolic leachates. The separation of yttrium has not been performed since the focus of the present study falls on opportunities in solvometallurgy for scandium recovery. However, it has been shown by the previous studies that yttrium can be well separated by gradient elution of the SILP with phosphoric acid. ${ }^{1}$

Speciation of Iron(III) in Aqueous and Ethanolic Leachates of the BR. It was demonstrated that the selectivity of the SILP for the investigated elements in the aqueous leachate differs from the selectivity for the elements in the ethanolic leachate (Figure 5 and Figure 7). The change in selectivity can impact the potential pretreatment of the BR and downstream processing. The source of variations in selectivity of the ion exchange process with the SILP lies in elementsolvent interactions and therefore in the formation of different species in aqueous and ethanolic solutions. The most drastic change was manifested by the difference in sorption of iron by the SILP from the two leachates. Therefore, the UV-vis absorption spectra were measured to elucidate the speciation of iron(III) in the two leachates (Figure 8).

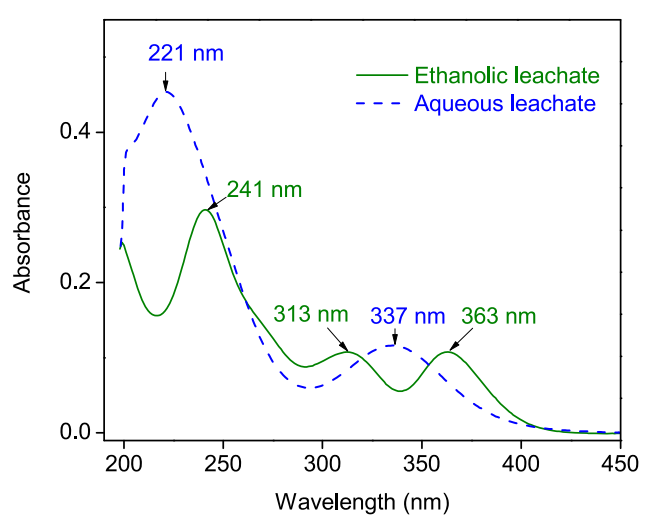

Figure 8. UV-vis absorption spectra of BR leachates with $0.7 \mathrm{~mol} \mathrm{~L}^{-1}$ water (aqueous leachate, dashed blue line) or with $0.7 \mathrm{~mol} \mathrm{~L}^{-1}$ ethanol (ethanolic leachate, full green line).

The absorbance maxima at 221 and $337 \mathrm{~nm}$ are observed most probably due to the presence of the $\left[\mathrm{Fe}\left(\mathrm{H}_{2} \mathrm{O}\right)_{5} \mathrm{Cl}\right]^{2+}$ complex. ${ }^{64}$ Therefore, in the aqueous leachate iron(III) is present as a cationic complex which is recovered by the SILP via the proton exchange mechanism. Absorption maxima in the ethanolic leachate are observed at 241, 313, and $363 \mathrm{~nm}$. This absorption spectrum shows a close similarity to that reported in the literature for the tetrachloroferrate(III) complex, $\left[\mathrm{FeCl}_{4}\right]^{-65,66}$ The experimental data confirm the hypothesis that iron(III) is predominantly present as an anionic complex in the ethanolic leachate when the concentration of chlorides is low (e.g., when leaching of BR is performed with $0.7 \mathrm{~mol} \mathrm{~L}^{-1}$ $\mathrm{HCl}$ in ethanol). The formed chloro complex enabled the separation of iron from other components of the BR leachate by elution of the SILP with ethanol. Highly concentrated chloride solutions (e.g., $>8 \mathrm{~mol} \mathrm{~L}^{-1}$ ) are required for iron(III) to form anionic chloro complexes in aqueous solutions at room temperature. ${ }^{65}$ Therefore, the elution of iron with ethanol is much more straightforward than, for instance, with concentrated aqueous chloride eluents.

\section{CONCLUSIONS}

Screening of the three sorbents $\left(\mathrm{SiO}_{2}, \mathrm{SiO}_{2}-\mathrm{TMS}-\mathrm{EDTA}\right.$, and the SILP) for recovery of scandium from water, ethanol, isopropanol, ethylene glycol, and PEG-200 solutions revealed the potential of the SILP for scandium separation from the ethanolic leachate of BR. The BR was leached by $0.7 \mathrm{~mol} \mathrm{~L}^{-1}$ $\mathrm{HCl}$ in ethanol or in water. The leaching efficiencies of scandium and a vast majority of other elements were similar to both lixiviants. However, the sodium concentration in the ethanolic leachate was significantly lower compared to that in the aqueous leachate due to the limited solubility of sodium chloride in ethanol. Moreover, silica gel formation was suppressed by leaching with $0.7 \mathrm{~mol} \mathrm{~L}{ }^{-1} \mathrm{HCl}$ in ethanol, unlike when the leaching was performed with $0.7 \mathrm{~mol} \mathrm{~L}^{-1} \mathrm{HCl}$ in water. In the breakthrough curve studies with the aqueous BR leachate, the uptake preference of the elements by the SILP was $\mathrm{Si} \approx \mathrm{Ti}<\mathrm{Na}<\mathrm{Ca} \approx \mathrm{Fe} \approx \mathrm{Al}<\mathrm{Sc}<\mathrm{Y}$. The sequence was in part reversed when the uptake of the elements was performed from the ethanolic leachate, that is, $\mathrm{Si}<\mathrm{Fe} \approx \mathrm{Ti}$ $<\mathrm{Sc}<\mathrm{Al}<\mathrm{Y}<\mathrm{Ca}<\mathrm{Na}$. The reversal in trend was partly rationalized based on the change in solvation of the metal ions in the ethanolic leachate. Iron(III) was easily separated from the majority of other components of the BR by elution with ethanol in column chromatography with the SILP. The formation of the tetrachloroferrate(III) complex, $\left[\mathrm{FeCl}_{4}\right]^{-}$, at low chloride concentrations in ethanolic solution enabled the selectivity of the column chromatography process. The formation of the negatively charged iron(III) chloro complexes at low chloride concentration and at room temperature is not feasible in the aqueous solution. About $84 \%$ of scandium was separated from other components of both leachates of the BR by elution with $0.1 \mathrm{~mol} \mathrm{~L}^{-1} \mathrm{H}_{3} \mathrm{PO}_{4}$. Still, a high sample throughput and concentration of scandium from the ethanolic leachate by the SILP was not achieved. Apart of iron and silicon, other major components of the ethanolic BR leachate were recovered by the SILP along with scandium. Nevertheless, the study gives new insights on how a simple change in solvent in which metals are dissolved greatly affects the entire process for metal recovery. The potential of solvometallurgy in complex metallurgical processes was demonstrated.

\section{ASSOCIATED CONTENT}

\section{Supporting Information}

The Supporting Information is available free of charge at https://pubs.acs.org/doi/10.1021/acs.iecr.0c02943.

Concentrations of elements in bauxite residue leachates $\left(\mathrm{mg} \mathrm{L}^{-1}\right)$ (Table S1), pictures of aged aqueous and ethanolic bauxite residue leachates (Figure S1), and FTIR spectra of the SILP after recovery of elements from the ethanolic leachate of BR (Figure S2) (PDF)

\section{AUTHOR INFORMATION}

\section{Corresponding Author}

Koen Binnemans - Department of Chemistry, KU Leuven, B3001 Leuven, Belgium; 이이이.org/0000-0003-4768-3606; Email: Koen.Binnemans@kuleuven.be

\section{Author}

Dženita Avdibegović - Department of Chemistry, KU Leuven,

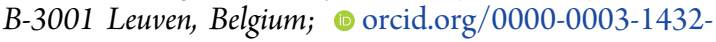
7672

Complete contact information is available at: 
https://pubs.acs.org/10.1021/acs.iecr.0c02943

\section{Funding}

The research leading to these results received funding from the European Research Council (ERC) under the European Union's Horizon 2020 Research and Innovation Programme: Grant Agreement 694078-Solvometallurgy for critical metals (SOLCRIMET).

\section{Notes}

The authors declare no competing financial interest.

\section{ACKNOWLEDGMENTS}

The authors are grateful to Thupten Palden for his help in the XRD analysis. Aluminum of Greece (Agios Nikolaos, Greece) and Stergiani Varvara Kapelari (KU Leuven) are acknowledged for providing the sample of bauxite residue.

\section{REFERENCES}

(1) Binnemans, K.; Jones, P. T.; Müller, T.; Yurramendi, L. Rare Earths and the Balance Problem: How to Deal with Changing Markets? J. Sustain. Metall. 2018, 4 (1), 126-146.

(2) Wang, W.; Pranolo, Y.; Cheng, C. Y. Metallurgical Processes for Scandium Recovery from Various Resources: A Review. Hydrometallurgy 2011, 108 (1-2), 100-108.

(3) Nikoloski, A. N.; Ang, K. L.; Li, D. Recovery of Platinum, Palladium and Rhodium from Acidic Chloride Leach Solution Using Ion Exchange Resins. Hydrometallurgy 2015, 152, 20-32.

(4) Rojste, J.; Aluminium, H. Scandium In Aluminium Alloys: Physical Metallurgy, Properties And Applications. Metall. Sci. Technol. 2013, 25 (2), 11-21.

(5) Evans, K. The History, Challenges, and New Developments in the Management and Use of Bauxite Residue. J. Sustain. Metall. 2016, 2 (4), 316-331.

(6) Ochsenkühn-Petropoulou, M. T.; Hatzilyberis, K. S.; Mendrinos, L. N.; Salmas, C. E. Pilot-Plant Investigation of the Leaching Process for the Recovery of Scandium from Red Mud. Ind. Eng. Chem. Res. 2002, 41 (23), 5794-5801.

(7) Yagmurlu, B.; Zhang, W.; Heikkilä, M. J.; Koivula, R. T.; Friedrich, B. Solid-State Conversion of Scandium Phosphate into Scandium Oxide with Sodium Compounds. Ind. Eng. Chem. Res. 2019, 58 (32), 14609-14620.

(8) Anawati, J.; Azimi, G. Recovery of Scandium from Canadian Bauxite Residue Utilizing Acid Baking Followed by Water Leaching. Waste Manage. 2019, 95, 549-559.

(9) Reid, S.; Tam, J.; Yang, M.; Azimi, G. Technospheric Mining of Rare Earth Elements from Bauxite Residue (Red Mud): Process Optimization, Kinetic Investigation, and Microwave Pretreatment. Sci. Rep. 2017, 7 (1), 1-9.

(10) Cardenia, C.; Balomenos, E.; Panias, D. Iron Recovery from Bauxite Residue Through Reductive Roasting and Wet Magnetic Separation. J. Sustain. Metall. 2019, 5 (1), 9-19.

(11) Rivera, R. M.; Xakalashe, B.; Ounoughene, G.; Binnemans, K.; Friedrich, B.; Van Gerven, T. Selective Rare Earth Element Extraction Using High-Pressure Acid Leaching of Slags Arising from the Smelting of Bauxite Residue. Hydrometallurgy 2019, 184, 162-174.

(12) Hertel, T.; Pontikes, Y. Geopolymers, Inorganic Polymers, Alkali-Activated Materials and Hybrid Binders from Bauxite Residue (Red Mud) - Putting Things in Perspective. J. Cleaner Prod. 2020, 258, 120610.

(13) Binnemans, K.; Jones, P. T.; Blanpain, B.; Van Gerven, T.; Pontikes, Y. Towards Zero-Waste Valorisation of Rare-EarthContaining Industrial Process Residues: A Critical Review. J. Cleaner Prod. 2015, 99, 17-38.

(14) Borra, C. R.; Pontikes, Y.; Binnemans, K.; Van Gerven, T. Leaching of Rare Earths from Bauxite Residue (Red Mud). Miner. Eng. 2015, 76, 20-27.
(15) Onghena, B.; Borra, C. R.; Van Gerven, T.; Binnemans, K. Recovery of Scandium from Sulfation-Roasted Leachates of Bauxite Residue by Solvent Extraction with the Ionic Liquid Betainium Bis(Trifluoromethylsulfonyl)Imide. Sep. Purif. Technol. 2017, 176, 208-219.

(16) Onghena, B.; Binnemans, K. Recovery of Scandium(III) from Aqueous Solutions by Solvent Extraction with the Functionalized Ionic Liquid Betainium Bis(Trifluoromethylsulfonyl)Imide. Ind. Eng. Chem. Res. 2015, 54 (6), 1887-1898.

(17) Avdibegović, D.; Regadío, M.; Binnemans, K. Efficient Separation of Rare Earths Recovered by a Supported Ionic Liquid from Bauxite Residue Leachate. RSC Adv. 2018, 8 (22), 1188611893.

(18) Avdibegović, D.; Zhang, W.; Xu, J.; Regadío, M.; Koivula, R.; Binnemans, K. Selective Ion-Exchange Separation of Scandium(III) over Iron(III) by Crystalline A-Zirconium Phosphate Platelets under Acidic Conditions. Sep. Purif. Technol. 2019, 215, 81-90.

(19) Avdibegović, D.; Yagmurlu, B.; Dittrich, C.; Regadío, M.; Friedrich, B.; Binnemans, K. Combined Multi-Step Precipitation and Supported Ionic Liquid Phase Chromatography for the Recovery of Rare Earths from Leach Solutions of Bauxite Residues. Hydrometallurgy 2018, 180, 229-235.

(20) Zhang, W.; Koivula, R.; Wiikinkoski, E.; Xu, J.; Hietala, S.; Lehto, J.; Harjula, R. Efficient and Selective Recovery of Trace Scandium by Inorganic Titanium Phosphate Ion-Exchangers from Leachates of Waste Bauxite Residue. ACS Sustainable Chem. Eng. 2017, 5 (4), 3103-3114.

(21) Roosen, J.; Van Roosendael, S.; Borra, C. R.; Van Gerven, T.; Mullens, S.; Binnemans, K. Recovery of Scandium from Leachates of Greek Bauxite Residue by Adsorption on Functionalized. Green Chem. 2016, 18, 2005-2013.

(22) Usuda, S. Studies on Rapid Ion-Exchange Separation of the Transplutonium Elements with Mineral Acid-Methanol Mixed Media. JAERI-1315 Japan 1989.

(23) Strelow, F. W. E.; Baxter, C.; Chemicai, N. Separation Of Tervalent Rare Earths And Scandium From Aluminium, Iron(III), Titanium(IV), And Other Elements By Cation-Exchange Chromatography In Hydrochloric Acid-Ethanol. Talanta 1969, 16, 1145-1151.

(24) Strelow, F. W. E.; Van Zyl, C. R.; Bothma, C. J. C. Distribution Coefficients of Elements and The Cation-Exchange Behavior in Hydrochloric Acid-Ethanol Mixtures. Anal. Chim. Acta 1969, 45, 8192

(25) Wilkins, D. H.; Smith, G. E. Ethanol-Water-Hydrochloric Acid Eluents Separations. Talanta 1961, 8, 138-142.

(26) Binnemans, K.; Jones, P. T. Solvometallurgy: An Emerging Branch of Extractive Metallurgy. J. Sustain. Metall. 2017, 3 (3), 570600.

(27) Giret, S.; Hu, Y.; Masoumifard, N.; Boulanger, J. F.; Estelle, J.; Kleitz, F.; Larivière, D. Selective Separation and Preconcentration of Scandium with Mesoporous Silica. ACS Appl. Mater. Interfaces 2018, 10 (1), 448-457.

(28) Dupont, D.; Brullot, W.; Bloemen, M.; Verbiest, T.; Binnemans, K. Selective Uptake of Rare Earths from Aqueous Solutions by EDTA-Functionalized Magnetic and Nonmagnetic Nanoparticles. ACS Appl. Mater. Interfaces 2014, 6 (7), 4980-4988.

(29) Avdibegović, D.; Regadío, M.; Binnemans, K. Recovery of Scandium(III) from Diluted Aqueous Solutions by a Supported Ionic Liquid Phase (SILP). RSC Adv. 2017, 7 (78), 49664-49674.

(30) Rudolph, W. W.; Pye, C. C. Aqueous Solution Chemistry of Scandium(III) Studied by Raman Spectroscopy and Ab Initio Molecular Orbital Calculations. J. Solution Chem. 2000, 29 (10), 955-986.

(31) Böhm, F.; Sharma, V.; Schwaab, G.; Havenith, M. The Low Frequency Modes of Solvated Ions and Ion Pairs in Aqueous Electrolyte Solutions: Iron(II) and Iron(III) Chloride. Phys. Chem. Chem. Phys. 2015, 17 (29), 19582-19591.

(32) Hemmes, P.; Rich, L. D.; Cole, D. L.; Eyring, E. M. Kinetics of hydrolysis of ferric ion in dilute aqueous solution. J. Phys. Chem. 1971, 75 (7), 929-932. 
(33) Coetzee, R.; Dorfling, C.; Bradshaw, S. M. Precipitation of Ru, $\mathrm{Rh}$ and Ir with Iron Ions from Synthetic Nickel Sulphate Leach Solutions. Hydrometallurgy 2018, 175, 79-92.

(34) Starov, V. M. Nanoscience Colloidal and Interfacial Aspects; CRC/Taylor \& Francis: Leichestershire, 2010; Vol. 147, pp 11141116.

(35) Brealey, G. J.; Evans, M. G.; Uri, N. Photoreduction of $\mathrm{FeCl}_{4}{ }^{-}$ in Alcohol. Nature 1950, 166, 959-960.

(36) Larenkov, A. A.; Bruskin, A. B.; Kodina, G. E. Preparation of Highly Purified ${ }^{68}$ Ga Solutions via Ion Exchange in Hydrochloric Acid - Ethanol Mixtures. J. Radioanal. Nucl. Chem. 2015, 305, 147-160.

(37) Guilminot, E.; Dalard, F.; Degrigny, C. Mechanism of Iron Corrosion in Water-Polyethylene Glycol (PEG 400) Mixtures. Corros. Sci. 2002, 44 (10), 2199-2208.

(38) Balijepalli, A.; Robertson, J. W. F.; Reiner, J. E.; Kasianowicz, J. J.; Pastor, R. W. Theory of Polymer-Nanopore Interactions Refined Using Molecular Dynamics Simulations. J. Am. Chem. Soc. 2013, 135 (18), 7064-7072.

(39) Poudel, L.; Podgornik, R.; Ching, W. Y. The Hydration Effect and Selectivity of Alkali Metal Ions on Poly(Ethylene Glycol) Models in Cyclic and Linear Topology. J. Phys. Chem. A 2017, 121 (24), $4721-4731$.

(40) Seisko, S.; Lampinen, M.; Aromaa, J.; Laari, A.; Koiranen, T.; Lundström, M. Kinetics and Mechanisms of Gold Dissolution by Ferric Chloride Leaching. Miner. Eng. 2018, 115, 131-141.

(41) Hendricks, D. W. Water Treatment Unit Processes Physical and Chemical; CRC/Taylor \& Francis: Boca Raton, 2006; pp 307-308.

(42) Davris, P.; Balomenos, E.; Panias, D.; Paspaliaris, I. Selective Leaching of Rare Earth Elements from Bauxite Residue (Red Mud), Using a Functionalized Hydrophobic Ionic Liquid. Hydrometallurgy 2016, 164, 125-135.

(43) Rivera, R. M.; Ulenaers, B.; Ounoughene, G.; Binnemans, K.; Van Gerven, T. Extraction of Rare Earths from Bauxite Residue (Red Mud) by Dry Digestion Followed by Water Leaching. Miner. Eng. 2018, 119, 82-92.

(44) Borra, C. R.; Blanpain, B.; Pontikes, Y.; Binnemans, K.; Van Gerven, T. Recovery of Rare Earths and Major Metals from Bauxite Residue (Red Mud) by Alkali Roasting, Smelting, and Leaching. J. Sustain. Metall. 2017, 3 (2), 393-404.

(45) Liu, Z.; Li, H. Metallurgical Process for Valuable Elements Recovery from Red Mud - A Review. Hydrometallurgy 2015, 155, 2943.

(46) Borra, C. R.; Mermans, J.; Blanpain, B.; Pontikes, Y.; Binnemans, K.; Van Gerven, T. Selective Recovery of Rare Earths from Bauxite Residue by Combination of Sulfation, Roasting and Leaching. Miner. Eng. 2016, 92, 151-159.

(47) Rivera, R. M.; Ounoughene, G.; Borra, C. R.; Binnemans, K.; Van Gerven, T. Neutralisation of Bauxite Residue by Carbon Dioxide Prior to Acidic Leaching for Metal Recovery. Miner. Eng. 2017, 112, 92-102.

(48) Alkan, G.; Yagmurlu, B.; Cakmakoglu, S.; Hertel, T.; Kaya, S.; Gronen, L.; Stopic, S.; Friedrich, B. Novel Approach for Enhanced Scandium and Titanium Leaching Efficiency from Bauxite Residue with Suppressed Silica Gel Formation. Sci. Rep. 2018, 8, 5676.

(49) Borra, C. R.; Blanpain, B.; Pontikes, Y.; Binnemans, K.; Van Gerven, T. Recovery of Rare Earths and Other Valuable Metals From Bauxite Residue (Red Mud): A Review. J. Sustain. Metall. 2016, 2 (4), 365-386.

(50) Wang, L.; Sun, N.; Tang, H.; Sun, W. A Review on Comprehensive Utilization of Red Mud. Minerals 2019, 9, 362.

(51) Bratton, G. J.; Currell, B. R.; Parsonage, J. R.; Thomas, M. J. K. Controlled Polymerization of Silicic Acids Derived from Mineral Silicates. J. Mater. Chem. 1993, 3 (4), 343-346.

(52) Lange, K. M.; Bergmann, U.; Hodeck, K. F.; Könnecke, R.; Schade, U.; Aziz, E. F. Shared Solvation of Sodium Ions in AlcoholWater Solutions Explains the Non-Ideality of Free Energy of Solvation. Phys. Chem. Chem. Phys. 2011, 13 (34), 15423-15427.
(53) Tam, P. W. Y.; Panias, D. Sintering Optimisation and Recovery of Aluminum and Sodium from Greek Bauxite Residue. Minerals 2019, 9 (10), 571.

(54) Kaußen, F. M.; Friedrich, B. Methods for Alkaline Recovery of Aluminum from Bauxite Residue. J. Sustain. Metall. 2016, 2 (4), 353364.

(55) Thomas, J. D. R. Some Aspects of Ion Exchange in Nonaqueous and Mixed Solvents. J. Chromatogr. A 1974, 102, 209-215.

(56) Pearson, R. G. Hard and Soft Acids and Bases. J. Am. Chem. Soc. 1963, 85 (22), 3533-3539.

(57) Marcus, Y. Ions in Solution and their Solvation; John Wiley \& Sons, Inc., 2015; pp 63-218.

(58) Ferron, C. J. Iron Control in Hydrometallurgy: The Positive Side of the Coin; SGS Minerals Services, Technical Paper 2006-05, 2006. https://www.sgs.com/-/media/global/documents/technicaldocuments/sgs-technical-papers/sgs-min-tp2006-05-iron-control-inhydrometallurgy.pdf (accessed on August 17, 2020).

(59) Prat, D.; Wells, A.; Hayler, J.; Sneddon, H.; Mcelroy, C. R.; Abou-Shehada, S.; Dunn, P. J. CHEM21 Selection Guide of Classicaland Less Classical-Solvents. Green Chem. 2016, 18, 288-296.

(60) Dagle, R. A.; Winkelman, A. D.; Ramasamy, K. K.; Dagle, V. L.; Weber, R. S. Ethanol as a Renewable Building Block for Fuels and Chemicals. Ind. Eng. Chem. Res. 2020, 59, 4843-4853.

(61) Du, H.; Zhou, F.; Pang, W.; Yue, Y. Synthesis and Characterization of Titanium Silicate Molecular Sieves with ZoriteType Structure. Microporous Mater. 1996, 7 (2-3), 73-80.

(62) Putan, A.; Putan, V.; Heput, T.; Socalici, A. Steel Treatment with Calcium-Aluminate Synthetic Slag and Addition of Titanium Oxide. Rev. Metal. 2013, 49 (1), 31-44.

(63) Persson, I. Ferric Chloride Complexes in Aqueous Solution: An EXAFS Study. J. Solution Chem. 2018, 47 (5), 797-805.

(64) Liu, W.; Etschmann, B.; Brugger, J.; Spiccia, L.; Foran, G.; McInnes, B. UV-Vis Spectrophotometric and XAFS Studies of Ferric Chloride Complexes in Hyper-Saline $\mathrm{LiCl}$ Solutions at $25-90{ }^{\circ} \mathrm{C}$. Chem. Geol. 2006, 231 (4), 326-349.

(65) Gamlen, G. A.; Jordan, D. O. Spectrophotometric Study of the Iron(III) Chloro-complexes. J. Chem. Soc. 1953, 1435-1443.

(66) Vander Hoogerstraete, T.; Wellens, S.; Verachtert, K.; Binnemans, K. Removal of Transition Metals from Rare Earths by Solvent Extraction with an Undiluted Phosphonium Ionic Liquid: Separations Relevant to Rare-Earth Magnet Recycling. Green Chem. 2013, 15 (4), 919-927. 